\title{
Transdifferentiation of cancer stem cells into endothelial cells
}

\author{
Caterina A. M. La Porta* \\ Molecular Oncology Laboratory, \\ Department of Biomolecular Science and Biotechnology, \\ University of Milan, \\ 20133 Milan, Italy
}

Received 19 January 2011; Accepted 30 May 2011

Abstract: Vasculogenic mimicry was first described as the unique ability of aggressive melanoma cells to express an endothelial phenotype and to form vessel-like networks in three dimensional cultures, "mimicking" the pattern of embryonic vascular networks and recapitulating the patternednetworks seen in patients with aggressivetumors correlated with poor prognosis. Recentworkshows the occurrence of alternative vasculogenic patterns is due to the presence of stem cell population (cancer stem cells, CSC) at least in melanoma and glioblastoma. I discuss new perspectives to target vasculogenic mimicry as an anti-vascular treatment strategy and the possible use of AQP1 as target. Interest in AQP1 as a target arises from the pivotal role it plays in the organisation of vascular network affecting the cytoskeleton.

(c) Versita Sp. z 0.0 .

The cancer stem cell (CSC) hypothesis suggests that neoplastic clones are maintained exclusively by a rare fraction of cells with stem cell proprieties. Like normal stem cells, these rare CSCs possess the extensive proliferative and self-renewal potential necessary to create a new tumor and generate a hierarchy of phenotypically diverse downstream cells, which are successively more limited in these properties. On the other hand, as in normal tissue stem cells, CSCs should display the ability to undergo a broad range of differentiation events. The transdifferentiative capacity of normal stem cells is a common property of CSCs. As an example, melanoma CSCs, like all the other CSCs, may transdifferentiate into diverse phenotypes [1], express neurogenic, angiogenic, vasculogenic and also lymphatic markers [1], and are able to organise a pseudovascular network in a physiological assay such as aorta ring [2]. Additional work demonstrated that more aggressive melanoma cells can revert to an undifferentiated, embryonic-like phenotype [3]. Moreover, aggressive melanoma cells express endothelium-associated genes and can form extracellular matrix rich vasculogenic like networks in three dimensional cultures [4-10]. Microarray analysis confirmed a genetic reversion of aggressive melanoma cells to an undifferentiated embryonic-like phenotype [11-13]. More recently, glioblastoma stem-like cells were observed to transdifferentiate into endothelial cells [14-16]. All together, the capability to transdifferentiate appears to be a way for the cells to become more plastic and adapt to different and adverse environmental conditions.

Vasculogenic mimicry was first described by the unique ability of aggressive melanoma cells to express an endothelial phenotype and to form vessel-like networks in three dimensional cultures, "mimicking" the pattern of embryonic vascular networks and recapitulating the patterned networks seen in patients with aggressive tumors correlated with poor prognosis [13]. In fact, the word "vasculogenic" was selected to indicate the generation of the pathway de novo and "mimicry" was used because the tumour uses cell pathways for transporting fluid in tissues that were clearly not blood vessels. Additional studies have reported vasculogenic mimicry in several other tumor types, including breast, prostate, ovarian, chorio-, lung carcinomas, synovial-, rhabdomyosarcoma, Ewing sarcomas and paeochromocytoma [17].

\section{*E-mail: caterina.laporta@unimi.it}


I believe that two important aspects must be emphasised: the first one is to develop new strategies targeting CSC subpopulations. The use of antiangiogenic drugs in combination with drugs acting on specific targets of CSC subpopulations might open up interesting new therapeutic perspectives. The second, novel aspect, is to use AQP1 as a target. According to the model proposed by Verkman and collaborators, AQP1 drives water influx, facilitating lamellipodia extension and cell migration [18]. While investigating the possible connection between AQP1 and cytoskeleton, our group recently showed that such a water channel through Lin7/beta catenin is expressed both by human endothelium and melanoma cells and affects the organization of the cytoskeleton [19]. We also proposed a model where AQP1 appears to be a critical scaffold for plasma-membrane associated multiprotein-complex to stabilise the cytoskeleton [20]. By combining Verkman's

\section{References}

[1] Monzani E., Facchetti F., Galmozzi E., Corsini E., Benetti A., Cavazzin,C., et al., Melanoma contains CD133 and ABCG2 positive cells with enhanced tumourigenic potential, Eur. J. Cancer, 2007, 43, 935-946

[2] Nicosia R.F., Ottinetti A. Growth of microvessels in serum-free matrix culture of rat aorta. A quantitative assay of angiogenesis in vitro, Lab. Invest., 1990, 63, 115-122

[3] Maniotis A.J., Folberg R., Hess A., Seftor E.A., Gardner L.M., Pe'er J., et al., Vascular channel formation by human melanoma cells in vivo and in vitro, vasculogenic mimicry, Am. J. Pathol., 1999, 155, 739-752

[4] Folberg R., Rummelt V., Parys-Van Ginderdeuren R., Hwang T., Woolson R.F., Pe'er J., et al., The prognostic value of tumor blood vessel morphology in primary uveal melanoma, Ophthalmology, 1993, 100, 1389-1398

[5] Makitie T., Summanen P., Tarkkanen A., Kivela T., Microvascular loops and networks as prognostic indicators in choroidal and ciliary body melanomas, J. National Cancer Institute, 1999, 91, 359-367

[6] Sakamoto T., Sakamoto M., Yoshikawa H., Hata Y., Ishibashi T., Ohnishi Y., et al., Histologic findings and prognosis of uveal malignant melanoma in japanese patients, Am. J. Ophthalmol., 1996, 121, 276-283

[7] Warso M.A., Maniotis A.J., Chen X., Majumdar D., Patel M.K., Shilkaitis A., et al., Prognostic significance of periodic acid-Schiff-positive patterns and our model, we suggested that AQP1 is deeply involved in the lamellipodium organisation because, in presence of local osmotic gradients like as at the tip of lamelllipodium, water is driven inside through AQP(s) leading to the disruption of scaffold proteins which are degraded through proteasoma (Lin7/beta catenin) [20]. The effect on the cell is the cleavage of actin [20].

AQP1 might be a useful target for a combined melanoma therapy for two main reasons. Firstly, in melanoma the expression of AQP1 might be crucial for the growth of the tumor through its involvement in the vasculogenic/angiogenic pathways. In fact, AQP1 plays a crucial role in the capability of the cells (endothelial or melanoma cells) to sprout in knocked out animals or in cells where AQP1 has been silenced by siRNA. Secondly, AQP1 targeting might contribute to target quiescent CSCs that may be resistant to conventional therapy.

in primary cutaneous melanoma, Clin. Cancer Res., 2001, 7, 473-477

[8] Rummelt V., Mehaffey M.G., Campbell R.J., Pe'er J., Bentler S.E., Woolson R.F., et al., Microcirculation architecture of metastases from primary ciliary body and choroidal melanomas, Am. J. Ophthalmol., 1998, 126, 303-305

[9] Shirakawa K., Kobayashi H., Heike Y., Kawamoto S., Brechbiel M.W., Kasumi F., et al., Hemodynamics in vasculogenic mimicry and angiogenesis of inflammatory breast cancer xenograft, Cancer Res., 2002, 62, 560-566

[10] Zhou Y., Fisher S.J., Janatpour M., Genbacev O., Dejana E., Wheelock M., et al., Human cytotrophoblasts adopt a vascular phenotype as they differentiate. A strategy for successful endovascular invasion?, J. Clin. Investigat., 1997, 99, 2139-2151

[11] Hendrix M.J., Seftor E.A., Hess A.R., Seftor R.E., Vasculogenic mimicry and tumor cell plasticity: lessons from melanoma, Nat. Rev. Cancer, 2003, 3, 411-421

[12] Seregard S., Spangberg B., Juul C., Oskarsson M., Prognostic accuracy of the mean of the largest nucleoli, vascular patterns, and PC-10 in posterior uveal melanoma, Ophthalmology, 1998, $105,485-491$

[13] Thies A., Mangold U., Moll I., Schumacher U., PAS-positive loops and networks as a prognostic indicator in cutaneous malignant melanoma, J. Pathol., 2001, 195, 537-542 
[14] Ricci-Vitaliani L., El Hallani S., Boisselier B., Peglion F., Rousseau A., Colin C., et al., A new alternative mechanism in glioblastoma vascularization: tubular vasculogenic mimicry, Nature, 2010, 468, 824-828

[15] Chen Y., Jing Z., Luo C., Zhuang M., Xia J., Chen $Z$., et al., Vasculogenic mimicry-potential target for glioblastoma therapy: an in vitro and in vivo study, Brain, 2010, 133, 973-982

[16] Dong J., Zhao Y., Huang Q., Fei X., Diao Y., Shen Y., et al., Glioma stem/progenitor cells contribute to neovascularization via transdifferentiation, Stem Cell Rev. Rep., 2010, Doi: 10.1007/s12015-0109169-7.
[17] Monzani E., La Porta C.A.M., Targeting cancer stem cells to modulate alternative vascularization mechanisms, Stem Cell Rev., 2008, 4, 51-56

[18] Verkman A.S., More than just water channels: unexpected cellular roles of aquaporins, J. Cell Sci., 2007, 118, 3225-3232

[19] Monzani E., Bazzotti R., Perego C., La Porta C.A.M., AQP1 is not only a water channel: it contributes to cell migration through Lin7/beta-catenin, Plos One, 2009, 4, e6167

[20] La Porta C.A.M., AQP1 is not only a water channel: it contributes to cell migration through Lin7/beta-catenin, Cell Adhesion and Migration, 2010, 4, 204-206 